\title{
Nuevas luces sobre María Lejárraga (1874-1974). Unas traducciones en la sombra de 1907
}

Inma Rodríguez-Moranta

Universidad Rovira i Virgili

\section{El enigma de la firma "Gregorio Martínez Sierra": estado de la cuestión}

María Lejárraga, una mujer en la sombra da título a la biografía con la que Antonina Rodrigo (1994) reivindicó la figura y obra de la autora riojana eclipsada por el nombre de su marido. A estas alturas es sobradamente conocido que la dramaturga, ensayista y activa militante progresista María Lejárraga (San Millán de la Cogolla, 1874 - Buenos Aires, 1974) dedicó buena parte de su longeva vida a escribir obras que firmaría solo Gregorio Martínez Sierra (Madrid, 1881-1947). Una profusa bibliografía surgida en los últimos veinte años ha despejado, al fin, muchas de las dudas que se cernían sobre la oscura cuestión de la autoría. Durante mucho tiempo se sostuvo que únicamente había "colaborado" en los escritos de Martínez Sierra, tesis que O'Connor desmintió ya en 1987 y que desarrolló ampliamente en su posterior ensayo Mito y realidad (2000) a partir de la correspondencia que mantuvieron los esposos y de diversas entrevistas con sus contemporáneos. Fue entonces cuando la prensa y la crítica española se hicieron eco del asombroso descubrimiento, según evidencian los artículos y trabajos aparecidos a lo largo del año 2000 (Ayén, Chas, Obiol, Rodríguez, Umbral, López Martínez). Las investigaciones del profesor Aguilera han vuelto a arrojar luz 
sobre esta materia, y sus recientes conclusiones tratan de conciliar las dos hipótesis antiguamente enfrentadas:

Ha habido, sobre todo en los últimos años, varias teorías, que van desde la autoría casi exclusiva de María hasta la defensa a ultranza de una decisiva colaboración de Gregorio en todas las obras. Creo que ninguno de los extremos se acerca a la verdad. Y menos en las obras dramáticas, porque en otros textos, como las traducciones, los libros de viajes, las conferencias y los ensayos feministas, parece evidente que fueron redactados únicamente por María. En cuanto al teatro, yo creo que, en su mayor parte, es fruto de una colaboración, en la que cada uno tenía su papel, podríamos decir: una vez trazado el plan de la obra, tarea que hacían casi siempre de forma conjunta y en algunas ocasiones podría hacer Gregorio solo, como se deduce de su epistolario, María se encargaba del proceso de escritura, que más tarde se revisaba conjuntamente o tras el contraste con la práctica escénica de los ensayos, en donde el papel de Gregorio, gran director de escena, era esencial; finalmente, María alumbraba la redacción definitiva, que era la que se publicaba. Si por autoría entendemos exclusivamente la redacción de las obras, entonces sí que hay que convenir que María fue la autora de la mayoría.

Aguilera, 2007

Lo cierto es que ninguno de los dos cónyuges llegó a aclarar nunca cómo se había desarrollado exactamente aquella misteriosa "colaboración". En sus memorias, la abnegada escritora desveló las razones por las que había permanecido, motu proprio, celosamente oculta. Al parecer, su entorno familiar destinó una fría acogida a su primera obra: Cuentos breves (1899). El profundo desencanto la impulsó a prometer que no volvería a figurar en las portadas de sus libros:

Ésta es una de las poderosas razones por las cuales decidí que los hijos de nuestra unión intelectual no llevaran más que el nombre del padre. Otra, que siendo maestra de escuela, es decir, desempeñando un cargo público, no quería empañar la limpieza de mi nombre con la dudosa fama que en aquella época caía como sambenito casi deshonroso sobre toda mujer literata.

Martínez Sierra, 2000: 75-76

La segunda razón aducida -el desfavorable contexto social para una mujer escritora, lastre secular- determinó que la radical decisión se mantuviera inquebrantable. Advirtamos, en primer lugar, que Lejárraga alude aquí a 
una "unión intelectual" y no a una autoría única, sintagma que refuerza la citada conclusión del profesor Aguilera. En segundo lugar, harto significativo es que firme sus memorias como "María Martínez Sierra", el nombre por el que, en efecto, quiso ser recordada en su compromiso con los ideales de la República y en su encomiable quehacer a favor del feminismo ${ }^{1}$. La escritora eligió figurar también con los apellidos del marido cuando fundó y capitaneó, en 1931, la Asociación Femenina de Educación Cívica (1931-1936) (Aguilera, 2008).

No obstante, nunca dejará de sorprendernos el tándem amoroso-literario Martínez Sierra-Lejárraga, uno de los enigmas psicológicos más llamativos de nuestra literatura. Reparemos en otro dato: María siguió publicando en estos términos incluso tras la separación física del matrimonio, y a sabiendas de que Gregorio había formado ya una sólida pareja con la actriz cubana Catalina Bárcena ${ }^{2}$, con la que el escritor madrileño tendría una hija. Con todo, estamos lejos de querer inmiscuirnos en su vida íntima para -movidos por un impulso vengativo- relegar a la sombra, ahora, los logros de Gregorio Martínez Sierra, destacado empresario teatral, pulcro editor y uno de los más brillantes intermediarios y agitadores culturales españoles en los albores del siglo XX (Fuster, 2003). En atinada reflexión de su biógrafo:

Creemos que María fue una mujer de extraordinario valor en el ámbito intelectual, en el político y, desde luego, en el más recóndito de su bondado-

\footnotetext{
${ }^{1}$ En relación con su obra teatral, su actividad política y otras facetas intelectuales de la escritora deben consultarse las diversas monografías enmarcadas en el proyecto de investigación “María Martínez Sierra (1874-1974)", subvencionado por el Instituto de Estudios Riojanos y dirigido por el profesor Juan Aguilera Sastre: Aguilera $(1995,2002,2006)$. Otra de las grandes especialistas en la obra de María Lejárraga es Alda Blanco (1999, 2001, 2003, 2006). El lector interesado puede encontrar estudios complementarios en Nieva de la Paz (1998), Lizárraga (2004), Bianchi (2006) y Checa (2009).

${ }^{2}$ En sus memorias, César González Ruano (2004: 115) evoca la pareja Martínez Sierra-Bárcena. La cita reza así: “A Gregorio Martínez Sierra le conocí en Madrid hace más de veinte años, cuando vivía en una villa por Cuatro Caminos. Luego le visité en Marruecos, donde vivía, con Catalina Bárcena siempre, en una casa que había amueblado al gusto árabe y tenía una granja que atendía personalmente Catalina. Mínimo y con la piel pegada a los huesos, era ya entonces Martínez Sierra un hombre sin edad. Las momias hacen difícil el cálculo de sus años. Personalmente, Martínez Sierra era muy simpático, delicado y de buen gusto. Catalina, todavía en 1935, cuando yo la vi en Marruecos, estaba deliciosa. Fueron una de las parejas más extrañamente atractivas de la vida española".
} 
sa aunque enérgica personalidad. Junto a ella ha de rescatarse y reconocerse la importancia de Gregorio Martínez Sierra que, no se olvide, fue renovador del teatro español, alma y timón de las dos mejores revistas del Modernismo (Helios, de 1903, y Renacimiento, de 1907), editor revolucionario y director de cine en Hollywood y en Argentina, de quien Rubén Darío dijo que "junta a su talento un espíritu generoso" y a quien el vitriólico Rafael CansinosAssens recordaba como un "hombre bueno y sencillo que lleva el éxito con tanta modestia".

Un somero recorrido por los últimos estudios dedicados a María Lejárraga nos permite asistir a la feliz restauración de su nombre en la fructífera producción teatral firmada por Martínez Sierra y a la reedición, todavía en curso, de su obra completa en el exilio americano (Martínez Sierra, 2009). Por otra parte, han sido objeto de análisis otras facetas intelectuales que sí aparecieron asociadas desde un inicio a "María Martínez Sierra": los libros de viajes, los discursos y los ensayos feministas.

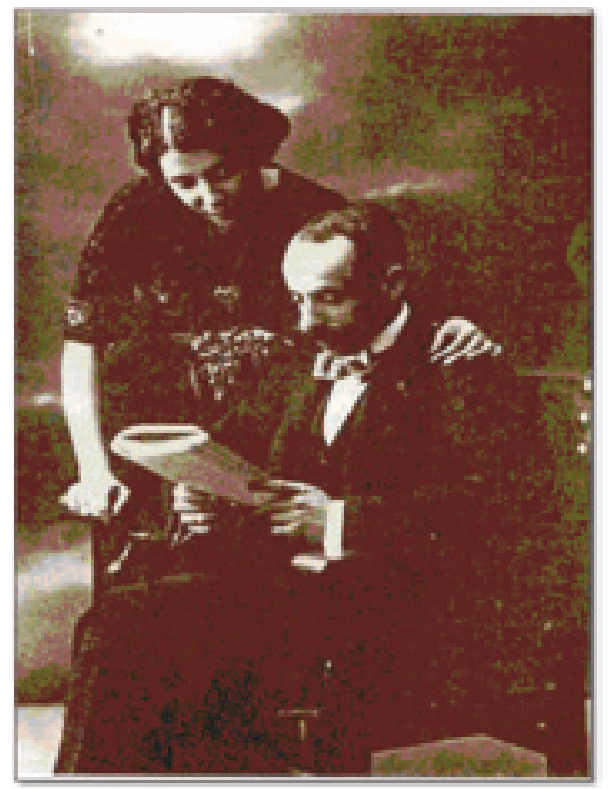

Figura 1. María Lejárraga y Gregorio Martínez Sierra en los años de máxima cooperación entre ellos. 
Queda ahora culminar esta labor con la divulgación de lo más valioso de su obra teatral -con ese proósito Serge Salaün (Martínez Sierra, 1999) reeditó Teatro de ensueño en la colección "Clásicos de Biblioteca Nueva"-, pero también resulta imprescindible valorar cuál es el papel que cumplió en el Modernismo español (Aguilera, 2007). En este sentido, es obligado acudir a las iniciativas culturales que el matrimonio emprendió en su particular defensa y promoción de la gente nueva: la fundación de revistas literarias. También aquí el nombre de María Lejárraga permanecería invariablemente en la sombra.

\section{Participación en las revistas modernistas Helios y Renacimiento. Traducciones olvidadas. María Lejárraga, anglófila}

Gregorio y María entraron de pleno en el mundo editorial al capitanear Vida Moderna (1901), publicación de breve existencia en la que participaron jóvenes modernistas al lado de representantes de la literatura realista. Dos años más tarde, asociándose con Juan Ramón Jiménez, Pedro González Blanco, Navarro y Ledesma y Pérez de Ayala fundaron la magnífica Helios (1903-1904), revista que encarna el cenit del modernismo (O'Riordan, 1970). Tras su desaparición, una parte del grupo fundador se dispersó; no así el pequeño núcleo que reunía a Gregorio, María y Juan Ramón Jiménez, cuya relación se hizo todavía más estrecha y maduró en los años siguientes, dando su más significativo fruto editorial en la revista Renacimiento (1907) ${ }^{3}$. Así lo hizo notar María Lejárraga en la misiva que remitió al poeta de Moguer: "Verdaderamente la co-responsabilidad futura de una revista imprime carácter. ¿No le parece a V. que también aumenta el cariño?" (Gullón, 1961: 49).

Aun sin detenerme en ello, quiero señalar la especialísima relación personal y literaria que unió a María Lejárraga y Juan Ramón, a quien ella consideró "el amigo perfecto" ${ }^{4}$. La correspondencia epistolar que se cruza-

\footnotetext{
${ }^{3}$ La génesis y los sucesivos avatares de la trayectoria de la revista Renacimiento se pueden rastrear en la relación epistolar que el matrimonio Martínez Sierra mantuvo con Juan Ramón Jiménez, reunida por Ricardo Gullón (1961) y por Alfonso Alegre (Jiménez, 2006a).

${ }^{4}$ Pueden encontrarse numerosos testimonios del cariño y la amistad de María hacia Juan Ramón en el capítulo "Helios" de las memorias de María Lejárraga (Mar-
} 
ron durante el primer tercio de siglo destila "una amistad romántica, llena de exaltación e intimidad", opina Ricardo Gullón (1961: 33), pues, entre muchas de las cartas que se guardan en el archivo de Juan Ramón, "pocas traslucen tanto cariño y tan leal admiración como la de esta amiga: confiante, animosa y cordial" (Gullón, 1961: 34). Lejárraga demostraba conocer bien al poeta y sabía remediar, con elegancia, desparpajo y una ironía rebosante de cariño, todo el pesimismo, las melancolías enfermizas y los frecuentes desplantes de su amigo "lunático" ${ }^{5}$. Al margen de esta entrañable amistad, María Lejárraga reconoció la valiosa colaboración juanramoniana en la mayor parte de las obras que firmó con el nombre de su marido. Así lo expresa en sus memorias:

Juan Ramón Jiménez encarnó para mí durante mucho tiempo el ideal de "fraternidad" entre hombre y mujer que tanto se sueña y casi nunca se consigue [...]. él ha puesto título a casi todas nuestras novelas largas y cortas: Tú eres la paz, Golondrina de sol, Margarita en la rueca. Cuando escribimos para acudir a un concurso literario La humilde verdad, como llegase el plazo de entrega y el manuscrito estuviese sin terminar, pasó la noche en claro copiando con nosotros, y así el manuscrito -aún no usábamos máquina de escribir- fue a manos del jurado con tres letras distintas: la nítida y perfecta de Juan Ramón Jiménez, la clarísima y neta de Gregorio Martínez Sierra, y la mía, un tanto desigual e indisciplinada.

Martínez Sierra, 2000: 232

Renacimiento apareció mensualmente entre marzo y diciembre sin perder nunca la extraordinaria calidad, el esmero tipográfico -un diseño elegante y austero- y el contenido puramente literario ${ }^{6}$. Si Helios es la revista del

tínez Sierra, 2000: 231-234) y en las “Cartas de María Martínez Sierra" recogidas por Gullón (1961: 71-111).

${ }^{5}$ Sirva como muestra de la inteligencia y del carácter entre comprensivo y burlón de la escritora, la respuesta que dio a Juan Ramón a una carta poco amable que este le había escrito: "Era sencillamente infame, pero a mí me gustó porque no hay como el mal humor para demostrar cariño. A usted la mía le pareció insignificante i qué le vamos a hacer! Las cartas de "alma, vida y corazón" sobre no ser para todos los días, son las que más correspondencia quieren, y a mí me hace muy poca gracia llenar hojitas de papel para un poeta, que de pascuas a ramos, pone una admiración detrás de mi nombre en una tarjeta odiosa... y se figura que con eso pone una pica en Flandes" (Gullón, 1961: 101).

${ }^{6}$ Renacimiento (1907) goza de una cuidada edición facsímil realizada por la editorial sevillana Renacimiento en 2002, con prólogo de Luis García Montero. 
Modernismo militante, Renacimiento es la gran publicación del Modernismo triunfante", sentenció Guillermo Díaz Plaja (1966: 44). En la portada de los diez números se estampó solo el nombre de Gregorio Martínez Sierra en calidad de director-, pero a través de los citados epistolarios constatamos que la responsabilidad recayó en los tres escritores, quienes se distribuyeron las tareas equitativamente. Refugiados en la seguridad de que sus posiciones literarias estaban ya consolidadas, esta vez quisieron que estuviera dirigida por un círculo íntimo, lo que les permitiría confeccionarla enteramente a su gusto. De hecho, Juan Ramón manifestó expresamente este deseo en carta a Gregorio: "Supongo que la revista la haremos los tres-María, usted, yo- únicamente. Y en gran secreto" (Jiménez, 2006: 168). Y Gregorio le confirmó el cumplimiento de tan anhelada libertad: "Desde luego haremos solos la revista" (Gullón, 1961: 48).

La revista se había gestado en 1906, en pleno periplo europeo del matrimonio Martínez Sierra ${ }^{7}$, viaje que les puso en contacto directo con ciertos autores extranjeros y con las nuevas tendencias literarias. Desde Londres, Gregorio escribe a Juan Ramón para exponerle la posibilidad de hacer realidad el proyecto (Gullón, 1961: 45-46). Se imprimiría en Madrid, pero la administración quedaría en París a cargo del jefe de la sección española de la célebre casa Garnier, que, en aquellos años, prestaba especial interés a la literatura española (Fernández, 1999) y había editado algunas de las obras más difundidas de los Martínez Sierra (Fischer, 1995: 234-243 y 281-427). Al señor Garnier lo habían conocido en el primer viaje del matrimonio a París, durante el otoño de 1905, cuando María había obtenido una beca de la Escuela Normal Central para estudiar nuevos métodos pedagógicos en Francia, Bélgica e Inglaterra. Aquella estancia fue especialmente fructífera,

${ }^{7}$ Poco después de la "muerte" de Helios, explica Enrique Fuster (2003: 77), "la quebradiza salud de Gregorio aconsejó al matrimonio alejarse de los aires viciados de Madrid. Una oportuna beca obtenida por María para estudiar la organización de las escuelas en Europa les hizo salir de España a primeros de octubre de 1905, y tras detenerse dos días en Burdeos, que no les entusiasmó, vino la fascinación de París. La ciudad entró de golpe y para siempre en el corazón de Gregorio, que se entregó impetuosamente al estudio de las nuevas tendencias del arte dramático [...]. En París frecuentaron la compañía de Isaac Albéniz, de Santiago Rusiñol, gran disfrutador a quien la vida le parecía algo extraordinariamente divertido, y de Enrique Gómez Carrillo, que les presentó al anciano y enérgico monsieur Garnier [...]". Entre febrero y abril de 1906, viajaron a Bruselas, Gante, Brujas y Colonia. En octubre fueron a Londres, donde probablemente conocieron al caballero dispuesto a sufragar los gastos de la revista de Renacimiento.

TRIANGLE 4 • June 2011 
pues, además, les permitió entablar amistad con importantes escritores, pintores y músicos españoles: Santiago Rusiñol, Manuel de Falla, Isaac Albéniz, Xavier Gosé y Eugeni d'Ors.

Uno de los aspectos más señalados de la revista de 1907 fue la apertura y el interés que mostró hacia las literaturas foráneas (Celma, 1991: 113). Como es sabido, el catálogo de traducciones publicadas en las revistas literarias nos permite abstraer, de un modo bastante fiable, las fases y la evolución en las preferencias estéticas de cada periodo. En este sentido, nos sorprende constatar que en los índices de las publicaciones madrileñas los nombres señeros del simbolismo, el decadentismo o el parnasianismo europeo no llegan a tener un mínimo espacio hasta el primer lustro del siglo XX. En los años anteriores, la presencia de letras extranjeras es menor y está fundamentalmente representada por figuras próximas a las tendencias naturalistas y realistas francesas o al espiritualismo ruso. Así, en las páginas de Germinal, La Vida Galante, Nuestro Tiempo, o Gente Vieja desfilan los nombres de Zola, Paul Bourget, Gustave Flaubert, Alphonse Daudet, los hermanos Goncourt, Dumas, Balzac, Maupassant, Dostoievsky, Turgueneff o Gorki. Fue excepcional, en este caso, La España Moderna, pionera en dar entrada a autores más cercanos a la moderna estética: entre 1890 y 1893 publicó diez textos de Banville; entre 1890 y 1891, cuatro de Gautier, y en 1892, dos piezas de Ibsen. En revistas más próximas al cambio de siglo, como Revista Nueva (1899) o Vida Nueva (1898-1900), encontramos algunas versiones de Ibsen o de Baudelaire. Pero el cambio definitivo en los gustos estéticos de los literatos españoles -acorde a la consolidación de la poética modernista- se pone de manifiesto con la publicación de traducciones de Maeterlinck, Mallarmé, Verlaine o D'Annunzio, entre otros, y con la recuperación de escritores de filiación romántica como Edgar Allan Poe, Longfellow o Leopardi, que irrumpen en algunas revistas madrileñas aparecidas entre 1903 y 1907 (Helios, Alma Española, La República de las Letras, Renacimiento), mostrando así el amplio abanico de influencias extranjeras confluyentes en el modernismo hispánico.

Tanto Helios como Renacimiento se preocuparon por mantenerse al corriente de las tendencias literarias europeas y por dar un aire internacional a su publicación. Esa voluntad se refleja no solo en el diseño externo de ambas publicaciones, inspiradas en el Mercure de France y en Vers et Prose, respectivamente, sino también en la progresiva introducción de literatura extranjera. La sección "Revista de revistas" de Helios incorporaba todos los meses reseñas de artículos recogidos, sobre todo, en publicaciones francesas 
como La Revue, Revue Bleue, Revue Blanche, La Renaissance Latine, Mercure de France, L'Ermitage y La Plume, "éstas últimas tan importantes en la difusión del simbolismo" (O'Riordan, 1970: 127). En Helios también aparecieron los mejores discípulos de los maestros simbolistas -Albert Samain, por ejemplo, se dio a conocer la poesía neoturca, se dedicaron cuatro extensos artículos a Shakespeare, y Poe apareció como el verdadero ídolo entre los poetas modernos. En cuanto al género teatral, destacó la presencia de Maeterlinck como dramaturgo predilecto entre la gente nueva ${ }^{8}$.

De acuerdo con su voluntad esencialmente poética, Renacimiento concede a la poesía un lugar primordial en la sección de letras extranjeras: predominan los versos o prosas líricas de tinte simbolista. Al lado de los indiscutibles maestros Verlaine y Mallarmé, y del italiano D'Annunzio, se incluye a los seguidores de estos: Rémy de Gourmont, Charles Guérin o Henri de Régnier. El género teatral aparece, de nuevo, unido al misticismo nórdico del belga Maurice Maeterlinck. Tampoco pierden de vista las literaturas orientales ni el importante componente romántico presente en el modernismo: con la publicación de Los Rubayata de Omar Khayyam vuelven los ojos hacia un Oriente lejano en el espacio y en el tiempo; y manifiestan su conocimiento e interés por el romanticismo anglosajón ofreciendo traducciones de poesía de Longfellow, un capítulo de la célebre obra de Thoreau, Walden, y el ensayo de Edgar Allan Poe Filosofía de la composición.

La labor traductora del fin de siglo puede descubrirnos datos muy interesantes. Es necesario, pues, discernir la importancia tanto de las traducciones como de los traductores. En Renacimiento esta tarea fue encomendada a escritores de prestigio que, a lo largo de su vida, desarrollaron una digna y fecunda labor paralela a su obra creativa o crítica: una mención especial merecen Ángel Vegue y Goldoni -que tradujo los poemas de Henri de Régnier- o Rafael Urbano -responsable de la traducción de Los ciegos de Maeterlinck-, impopulares en la actualidad, aunque fueron figuras destacadas en el mundo intelectual español de la época por su vinculación a la Institución Libre de Enseñanza y al Ateneo de Madrid. Sobradamente conocidos son, en cambio, los casos de Enrique Díez-Canedo -traduce en Renacimiento a D'Annunzio y a Charles Guérin- y de Juan Ramón Jiménez -ofrece versiones de Rémy de Gourmont-, quienes se conocieron a través

\footnotetext{
${ }^{8}$ Para no sobrepasar el ámbito de este trabajo, estos apuntes pretenden dar una idea de la preocupación de la revista Helios por la literatura extranjera. Se recomienda ver el capítulo en el que O’Riordan (1970: 127-134) analiza y ofrece numerosas referencias sobre esta cuestión.
} 
de Gregorio Martínez Sierra, e iniciaron una larga amistad gracias a la participación de Díez-Canedo en Renacimiento.

Dicho sea de paso, el contacto con el matrimonio Martínez Sierra fue provechoso para las inquietudes literarias del entonces joven poeta de Moguer, pues "lo sumerge en un ambiente de actividad cultural donde la traducción está a la orden del día. Traductores de Shakespeare, Rossetti, Thoreau y Longfellow -quizás también de Shelley-, el matrimonio pone su biblioteca a su disposición" (González Ródenas, 2005: 25). Hemos de destacar también el papel de Carlos Navarro Lamarca, a cuya biblioteca Juan Ramón era asiduo, y su platónico idilio con la norteamericana Luisa Grimm de Muriedas (Young, 1976), a quien conoció, curiosamente, gracias a María Lejárraga, buena conocedora y apasionada lectora de la poesía angloamericana. Fue ella quien lo introdujo en la obra de Poe, Blake, Tennyson, Whitman, Yeats, Byron, Keats, etc. Todo ello contribuyó a que Juan Ramón se interesara vivamente por otras literaturas -además de la francesa- que influirían en su posterior evolución poética. Más tarde llegaron las traducciones de Rabindranath Tagore y de literatura anglosajona que realizó con Zenobia Camprubí.

Sobre una traducción olvidada del autor bengalí, precisamente, llama la atención Agustín Coletes (2001) en el único asedio que se ha hecho a la labor traductora de María Lejárraga. Según documenta el investigador, el 15 de agosto de 1915 apareció en la prestigiosa revista Blanco y Negro una sección titulada "La luna creciente (poemas de madres a hijos), escritos en lengua bengalí por Rabindranaz Tagor". En ella se especificaba que la versión partía de las "autotraducciones" inglesas del propio autor. La firmó, como era de esperar, Gregorio Martínez Sierra (Coletes, 2001: 123).

Queda, pues, mucho trabajo por hacer, pues se deberían rescatar y analizar no solo las numerosas traducciones editadas en libro firmadas por el escritor madrileño -debidas en realidad a la pluma de su esposa-, sino también aquellas que pueblan las desatendidas revistas de la época.

Con el objetivo de contribuir, modestamente, al rescate de la faceta traductora de María Lejárraga, me gustaría aclarar aquí que fue ella quien realizó la mayor parte de las traducciones aparecidas en Renacimiento, aunque nunca las firmaran, en este caso, ni ella ni su marido. María era políglota y gozaba de un rico conocimiento de la literatura europea contemporánea. No en vano, había vertido al español gran parte de los textos extranjeros de Helios: Maeterlinck, Henri de Régnier, Georges Rodenbach y Maurice Rollinat (Rodrigo, 1994: 50). La novedad es que, en la revista de 1907, Lejárraga 
se ocupa, sobre todo, de las traducciones de literatura norteamericana, de la que se tenía escaso conocimiento directo en España. Debe consignarse que ambos, Gregorio y María, sentían un vivo entusiasmo anglófilo. Coletes ofrece importantes datos al respecto:

Gregorio, que se educa en el Liceo Francés de Madrid, aprende inglés tras concluir el bachillerato. María, vástago de familia ilustrada, se educa en la Escuela Normal de Madrid y, cuando conoce a Gregorio, es ya profesora de inglés, francés e italiano en una academia madrileña. Juntos viajarán, entre otros países, por Gran Bretaña, llegando a publicar un libro -El peregrino ilusionado, 1912- que recoge las impresiones de su visita. La colaboración literaria entre ambos incluirá la traducción, adaptación y consiguiente estreno, normalmente en el Teatro Eslava y entre 1917 y 1923, de distintas obras de dramaturgos de expresión inglesa, clásicos y modernos [...]

Coletes, 2001: 126

Durante el proceso de gestación de Renacimiento, Gregorio había hecho una primera adjudicación de las traducciones, que anunció epistolarmente a Juan Ramón Jiménez: "Encárguese usted de traducir varios trabajos de Vers et prose. María se ocupará de las traducciones inglesas, y yo de las catalanas" (Gullón, 1961: 48). A pesar de que en la revista no se dé noticia alguna de la responsabilidad de María Lejárraga como traductora, podemos afirmar con toda seguridad que, por lo menos, son suyas las versiones de Los Rubayata de Omar Khayyam -que elabora a partir de la versión inglesa de Fitzgerald-, del capítulo "Solitude" del Walden de Thoreau, así como de los poemas de Longfellow, todos ellos representativos de los gustos de la época y traducidos por primera vez al castellano. En los sumarios de los tres primeros números de Renacimiento que Martínez Sierra remite al poeta de Moguer aparecen referencias explícitas a esta cuestión:

Los Rubayata (Un poema persa estupendo, que habrá usted visto en Vers et prose. Le ha traducido (muy bien) María del inglés)

Henry David Thoreau -La vida en los bosques. (Muy interesante. Prosa. Traducción de María) [...]

Longfellow -Poesías. (Traducción de María -Con motivo del Centenario.) Stéphane Mallarmé -Poemas en prosa (Traducción de María). 
Según la citada misiva, María también se habría ocupado de textos franceses, concretamente de los poemas en prosa de Mallarmé ("El fenómeno futuro", "La pipa", "Queja de otoño" y "Estremecimiento de invierno") (Renacimiento, 2002 [1907]: 357-360). Dado que las traducciones sin firma publicadas en los primeros números de Renacimiento eran de María Lejárraga, no sería demasiado arriesgado suponer que ella también pudo realizar el resto de las versiones anónimas de la revista: las traducciones de Verlaine que ven la luz en la séptima entrega ${ }^{9}$ y la primera traducción castellana del célebre ensayo de Edgar Allan Poe, Filosofía de la composición.

\section{Importancia de sus traducciones de literatura norteamericana en el contexto modernista: H. W. Longfellow, H. D. Thoreau y E. Allan Poe}

¿Qué lugar ocupa la literatura anglosajona en el panorama literario modernista español? Es difícil responder a esta pregunta, pues a la historiografía española le falta tal vez una visión descriptiva completa y una valoración global de la presencia, difusión e influencia de la literatura anglosajona en nuestras letras modernistas. Es obligado citar, sin embargo, el interesante estudio de Carlos Clavería (1970) sobre la presencia de Carlyle en Unamuno, o los trabajos de Carmen Pérez Romero $(1979,1987,1992)$ que analizan la influencia de la poesía anglosajona en Juan Ramón Jiménez, además de algunos capítulos o trabajos especializados que se han elaborado desde el ámbito de la historia de la traducción, algunos de los cuales se mencionarán a lo largo del presente estudio.

Parece incuestionable que el influjo y la difusión en España de las letras francesas aventajan en mucho a las anglosajonas, pero obviar el papel que desempeñaron estas últimas en la renovación estética finisecular de las letras hispánicas supone igualmente un vacío que urge reparar en nuestros

\footnotetext{
${ }^{9}$ Podríamos pensar que las versiones de Paul Verlaine fueron responsabilidad de Juan Ramón Jiménez o de Manuel Machado, conocidos traductores del poeta francés en aquella época. No hemos encontrado, sin embargo, traducciones de estos poemas en la obra que recoge las versiones de literatura extranjera realizadas por el poeta de Moguer (Jiménez, 2006b); y aunque sí las encontramos en el volumen de traducciones de Manuel Machado (Verlaine, s. a), se trata de versiones diferentes, pues están vertidas a la prosa poética.
} 
estudios literarios: ¿no recogió el simbolismo francés un gran caudal del romanticismo angloamericano? Es cierto que en España, durante algún tiempo, la literatura norteamericana se conoció de manera indirecta a través de las traducciones francesas; pero no es menos cierto que la poética modernista no se puede entender sin el componente idealista y romántico heredado de la literatura angloamericana del siglo XIX. Finalmente, cabe notar que el valor e interés de dichas traducciones no ha pasado desapercibido a los especialistas: Lanero y Villoria (1996: 151) se han referido a Renacimiento como "una publicación excelente que, durante su breve existencia, dedicó especial atención a la literatura norteamericana".

Nos llama la atención el que, entre Longfellow, Edgar Allan Poe y Thoreau, tal vez sea el primero (Henry Wadsworth Longfellow, 1807-1882) -el menos conocido y estudiado en nuestros días- el que gozó de mayor número de traducciones españolas en las revistas del fin de siglo y de un conocimiento directo a través de ediciones aparecidas en Estados Unidos e Hispanoamérica (Englekirk, 1942), y no mediante las versiones francesas (Lanero y Villoria, 1996: 145), como, en cambio, sucedió con la obra de E. A. Poe, manejada por nuestros literatos, durante bastante tiempo, a través de las versiones de Mallarmé y Baudelaire. Las primeras traducciones de Longfellow editadas en libro en España son las de Teodor Llorente (1875) y las de Vicente Arana (1876). En los años que siguen a la aparición de estos volúmenes encontramos numerosos poemas traducidos en revistas culturales o literarias, entre las que cabe destacar Revista Contemporánea (Paz, 1950), pues, entre 1877 y 1896, ofreció once textos del escritor norteamericano, a los que debemos sumar otras versiones impresas en La España Moderna o Nuestro Tiempo (Lanero y Villoria, 1996: 150-51). Por nuestra parte, además de las poesías traducidas por María Lejárraga para el segundo número de Renacimiento (Longfellow, 2002 [1907]) ${ }^{10}$, hemos localizado traducciones poéticas de Longfellow en Germinal (1897, núm. 14) y en La República de las Letras (1905, núms. 1 y 11).

Creemos que el lector español acogió tan calurosamente a Longfellow por su agradecida visita a nuestro país en 1827, y por el entusiasmo que el escritor mostró por las letras hispánicas a su vuelta a Estados Unidos. Esa simpatía le llevó a verter al inglés obras canónicas de nuestra literatura, como las Coplas de Jorge Manrique y numerosas composiciones del Siglo de Oro. En Renacimiento, su presencia está justificada por la conmemoración del primer centenario del nacimiento del poeta, del que también se hizo eco $\mathrm{La}$

${ }^{10}$ Las citas de la revista Renacimiento se toman de la edición facsímil de 2002. 
Lectura (enero de 1907: 365). Todo parece indicar, sin embargo, que el paso del tiempo no ha favorecido la lectura y recepción crítica de Longfellow: si revisamos la bibliografía contemporánea no hallamos apenas estudios sobre este poeta, y resulta difícil encontrar reediciones actuales de sus obras. Desde luego, no le habrá favorecido el hecho de que comúnmente haya sido clasificado dentro de los llamados "Poetas domésticos", junto a W. C. Bryant, J. R. Lowell, J. G. Whittier -siendo el más célebre, sin duda, del grupo- y otros que "recientemente han pasado a un plano inferior por más que en algún momento parecieron tener asegurado su lugar en el canon de la literatura americana", apunta Thomas Wortham (1991: 279).

Una fortuna bien distinta corrió Henry David Thoreau (1817-1862), pues aunque hoy nadie duda en situarlo entre las figuras señeras del romanticismo norteamericano -junto a Edgar Allan Poe, Emerson, Walt Whitman o Herman Melville-, durante buena parte del siglo XIX fue injustamente denostado por el público y la crítica. De hecho, no fue hasta muy entrado el siglo XX cuando su obra recibió el merecido reconocimiento que favorecería la publicación de numerosas reediciones y traducciones en todo el mundo. De ahí que las primeras traducciones castellanas de Walden; or life in the Woods (Thoreau, 1854) -hoy considerada obra maestra de las letras norteamericanas- no vieran la luz hasta mediados de los años cuarenta, cuando se publicaron dos versiones en Buenos Aires (Thoreau, 1945, 1949). Es digno de mención, pues, reclamar que, muchos años antes de la aparición de estas dos versiones hispanoamericanas, el público lector madrileño ya había podido leer en castellano una primicia de Walden, pues en abril de 1907 la revista Renacimiento publicó una versión anónima del capítulo "Solitude" (Thoreau, 2002 [1907]), que se convertiría en el primer texto en castellano de Thoreau impreso en España. Por esta razón, se ha considerado un documento raro y excepcional. Fernando Montes (1994) no solo subraya la importancia y calidad literaria de dicha traducción, sino que también elogia el papel que desempeñó Renacimiento en la difusión del movimiento modernista y su meritoria labor traductora:

El acervo de traducciones al castellano de Thoreau anteriores a dicha fecha [1945] es francamente escaso [...]. Lo único con lo que contamos previamente es con una traducción de una biografía escrita por Henry Seidel Canby, que aparecería en Buenos Aires en 1944, y con un capítulo de Walden -concretamente aquél titulado "Solitude"-, que se halla incluido en el número 2 de la revista Renacimiento. Dicho fragmento constituye la primera versión conservada en lengua castellana de una obra de Thoreau y se la pue- 
de considerar como una joya de valor inapreciable, no tanto por su calidad intrínseca como por su interés histórico y arqueológico. La versión, realizada por un traductor anónimo, data del año 1907. La revista Renacimiento, fundada y dirigida por el poeta y dramaturgo Gregorio Martínez Sierra, fue de una importancia crucial en la difusión del movimiento modernista por nuestro país y asimismo contribuyó poderosamente a fortalecer el interés del público español por las letras universales mediante la frecuente inserción de traducciones de fragmentos breves de obras realizadas por autores extranjeros.

Montes, 1994: 146

Hoy sabemos, afortunadamente, que el "traductor anónimo" no era otro que María Lejárraga. No podemos pasar por alto que la presencia de Walden en Renacimiento debe enmarcarse en la corriente antiindustrialista que recorre el fin de siglo ${ }^{11}$. Recordemos que el romántico canto a los beneficios de una vida sencilla en contacto con la naturaleza -lejos de los afanes materialistas de la sociedad industrial-, el paisaje descrito con detallismo y precisión positivista, así como el elogio de la búsqueda de una soledad necesaria para el diálogo introspectivo del hombre son principios filosóficos y éticos fundamentales en la obra de Thoreau.

Antes de valorar la fidelidad de la traducción respecto al original, debemos tener presente que trasladar Walden de 1854 a otro idioma es una empresa difícil, porque el inglés de Thoreau es especialmente conciso y denso en sus alusiones a la flora y fauna de la Nueva Inglaterra. La traducción de Lejárraga dista mucho de alcanzar la perfección, pues posee ciertas inexactitudes, supresiones, adiciones y alteraciones del sentido original (Montes, 1994: 147-150), además de estar poblada de rasgos lingüísticos que resultan anticuados para el lector actual (los pronombres personales objetivos

\footnotetext{
${ }^{11} \mathrm{El}$ antiindustrialismo convive, en la época modernista, con la confianza y el entusiasmo en el progreso técnico y científico. La revista Renacimiento, sin embargo, se caracteriza por un rechazo de la modernización material del país. También en esto sigue la estela de Helios, según afirma M. Pilar Celma (1989: 81): "En los "glosarios" de Helios aparecen como tema recurrente los accidentes de tráfico -atropello de niños por tranvías (n. 1), muerte en carreras de automóviles (n. 2 y 4)-, como una consecuencia nefasta del progreso. Desde el principio se saca ya una triste conclusión “QQuién sabe lo que puede el espíritu gris del progreso!”. La deshumanización que implica esa subordinación e impotencia del hombre ante la máquina queda patente cuando se afirma: "La industria modernísima quema a un pobre hombre en aras de su exhibicionismo sórdido"'".
} 
en forma enclítica "respondíle", "fuíme", "traéme", por ejemplo). Pero son precisamente algunas de estas marcas de época, junto con la sensibilidad y el talento creativo de la escritora-traductora, las que hacen de este texto un "excelente producto, dotado a la par de una magnífica factura técnica y de un apreciable aliento artístico" (Montes, 1994: 147).

Finalmente, para valorar el influjo y la recepción de la obra de Edgar Allan Poe (1809-1849) en la literatura modernista española continúa siendo indispensable acudir al estudio de J. E. Englekirk (1934) y a los diversos trabajos que se han realizado en el ámbito de la traductología (Lanero, Santoyo y Villoria, 1993; Lanero y Villoria, 1996: 93-129; Rodríguez GuerreroStrachán, 1999). Únicamente me gustaría resaltar la importancia de la aparición de Poe en las revistas de comienzos de siglo, en un momento en que la cultura española parecía estar solo abierta al influjo francés. Hemos lanzado la hipótesis de que Lejárraga fue también la responsable de la primera traducción castellana del ensayo Filosofía de la composición (Poe, 2002 [1907]), texto de gran interés, pues, además de perfilar y justificar elementos fundamentales de la poética romántica, anticipa aspectos que caracterizarán la poesía moderna. En particular, su ars poetica se podrá vincular a la evolución estética de Juan Ramón Jiménez, poeta que en esas fechas empezaba ya a sentirse deslumbrado por la lírica anglosajona.

Es sobradamente conocido el papel determinante que la obra del norteamericano cumplió en la génesis de la estética contemporánea -simbolistas franceses y vanguardias del siglo XX son deudores de Poe, y del romanticismo en general-, en parte gracias a la labor traductora y difusora que llevaron a cabo Baudelaire y Mallarmé. Hasta tal punto es notable la afinidad estética entre estos poetas que, en palabras de Octavio Paz (1993: 162), "Baudelaire descubre en Poe a su semejante. Poe es el primer mito literario de los europeos [...] es el primer escritor americano convertido en mito". El culto a Poe iniciado en Francia se extendió a todas partes; llegó antes a Hispanoamérica -a través de Julio Herrera Reissig, José Asunción Silva y Rubén Darío- que a España; de ahí que la primera edición de El cuervo (The Raven, 1845) traducida directamente del inglés la realizara el venezolano Juan Antonio Pérez Bonalde (Poe, 1887), versión que tuvo bastante éxito aquellos años y fue sucesivamente reeditada en otros lugares. Aunque en la segunda mitad del XIX en España se habían publicado numerosas traducciones de los relatos fantásticos, a menudo estas se hacían a través de las versio- 
nes francesas de Baudelaire ${ }^{12}$, la mayor parte anónimas y sin rigor crítico alguno. Por otra parte, "lo que sorprende a primera vista es que no se tradujera en esa época ningún poema de E. A. Poe. El único que se traduce es El cuervo y se edita en Nueva York", advierte Rodríguez Guerrero-Strachán (1999: 86). En efecto, "el conocimiento de la obra de Poe fue incompleto: apenas sí se lo conoció como poeta hasta principios del presente siglo" (Lanero, Santoyo y Villoria, 1993: 159), concretamente en la primera década y a través de revistas literarias, como ya notó Englekirk:

The important literary journals of their creed are such short-lived but vital reviews as Helios, Renacimiento and Ateneo. Evidence of Poe's influence in Spain must be sought in the literary production from 1900 to 1910.

\section{Englekirk, 1934: 150}

Los lectores tuvieron que esperar hasta 1904 para leer The Raven en traducción española, fecha en que la revista Helios publicó una temprana versión firmada por el teosofista Viriato Díaz Pérez (Poe, 1904). En palabras de O'Riordan (1970: 132), fue "el suceso más importante en el campo de la literatura extranjera durante la vida de Helios" (O'Riordan, 1970: 132), opinión coincidente con la de Englekirk (1934: 66-67). En ese mismo número de la revista encontramos unas "Notas y ensayos de una traducción de El Cuervo de Edgardo Poe" (Díaz Pérez, 1904) redactadas por el propio traductor. Díaz-Pérez (1904: 351-52) reconoce el carácter revolucionario del genio romántico americano y establece una relación entre su poética y las tendencias literarias y filosóficas modernas, especialmente en el simbolismo místico de Maeterlinck.

El interés por la poesía del célebre norteamericano no decayó en los años siguientes. En 1907, la revista Ateneo publicó una nueva versión de El cuervo. El traductor esta vez fue Ignacio Mariscal, y el poema vino precedido de una carta de Amado Nervo dirigida a Mariano Miguel de Val. En ella, el

${ }^{12}$ Es oportuna la observación enunciada por Lanero, Santoyo y Villoria (1993: 160): “El castellano habría necesitado de un Baudelaire español que hiciera aquí lo que el autor de Las flores del mal hizo en francés, alguien con sensibilidad similar, con similares conocimientos lingüísticos, con similar fervor por la obra de Poe. Y no lo hubo. Carentes de un Baudelaire español, o hispanoamericano, nuestros traductores se limitaron a traducir del francés. Y así lo hicieron durante casi medio siglo, a pesar de que un alto porcentaje de ellos nada dicen al respecto, y consecuentemente la versión pasa entonces como hecha directamente del inglés". 
escritor mejicano lamentaba la escasa atención prestada en Madrid a la poesía americana y, concretamente, a la obra de Poe: "los ojos de España están demasiado vueltos a Francia"; "la vecindad ha hecho que las cosas pasen de otra manera" (Nervo, 1907: 334), afirmación que justificó aludiendo a un buen número de escritores hispanoamericanos que se habían ocupado de la literatura yanqui.

Si bien Helios había reconocido el liderazgo de Poe entre los poetas modernos, Renacimiento tomó el relevo y dio a conocer, en esta ocasión, su interesante faceta como teórico literario. Así, en la última entrega acoge una traducción anónima -hemos lanzado la hipótesis, muy probable, de que hubiera corrido a cargo de Lejárraga- de Filosofía de la composición (Poe, 1907; The Philosophy of Composition, 1846), ensayo metapoético complementario a El cuervo. Este dato nos ayuda a comprender que, a lo largo de la primera década del siglo XX, había crecido el interés por la obra de Poe -dos años más tarde se publicó en Madrid una edición de su poesía prologada por Rubén Darío (Poe, 1909) - y empezaba a conocerse la amplitud de facetas del escritor norteamericano: no solo sus cuentos fantásticos, tan leídos en la segunda mitad del siglo XIX español, sino también su poesía y sus teorías literarias.

La traducción ha sido citada por diversos investigadores (Young, Rodríguez Guerrero-Strachán, González Ródenas, etc.), que han subrayado su carácter inédito en el panorama editorial español, así como la modernidad que desprenden las teorías poéticas contenidas en él. Si cotejamos el texto inglés con la versión de Renacimiento, advertimos que se trata de una traducción fidelísima al original. Probablemente el género ensayístico no hubiera permitido una versión libre o poética -como la de Walden-, sin desvirtuar el rigor de la argumentación lógica del discurso. De hecho, las teorías estéticas de Poe destacan no solo por su modernidad, sino también por la lucidez, la simplicidad y el exquisito rigor metodológico, pues, a juicio de Bowra (1972: 196): "Aunque gusta del misterio en poesía y en el cuento, no lo emplea en la prosa destinada a exponer y a explicar [...]. En realidad, su estilo de argumentación tiene más de francés que de inglés, y no es de extrañar que haya impresionado a escritores franceses".

Respecto al responsable de la traducción, solo Howard Young (1981: 222) aventura el nombre de María Lejárraga, tesis que apoya en la circunstancia de que, en aquellas fechas, compartía con Juan Ramón Jiménez -y con Luisa Grimm- la afición por la literatura norteamericana. Y, sobre todo -apostillamos nosotros- porque ella había traducido el resto de los textos ingleses 
de la revista, incluida la versión (inglés-español) del largo poema persa de Omar Khayyam, Los Rubayata.

En síntesis, nos gustaría subrayar el fino sentido crítico que, en el contexto del modernismo, manifestaron los Martínez Sierra en la selección y divulgación de literaturas foráneas. Especialmente, hemos pretendido iluminar una pequeña parcela del amplio predio de traducciones de María Lejárraga, que esperamos completar en un futuro cercano, para poder incorporar definitivamente esta faceta de traductora en la sombra a su ya reconocida labor creativa y crítica.

Sirvan también estas páginas como recuerdo y homenaje a la labor silenciosa y oculta de tantos traductores anónimos del fin de siglo cuyo trabajo, aun habiendo contribuido a dar entrada a nuevas ideas y tendencias en España, no gozó de prestigio ni de reconocimiento social; un reconocimiento que Lejárraga nunca buscó para sí, pero cuyo rescate es un deber y un gozoso descubrimiento para nosotros.

\section{Traducciones publicadas en Renacimiento (1907) atribuibles a María Lejárraga}

\begin{tabular}{|c|c|c|c|c|}
\hline $\begin{array}{l}\text { AUTORES } \\
\text { TRADUCIDOS }\end{array}$ & TEXTOS & $\begin{array}{l}\text { NÚMERO Y } \\
\text { FECHA }\end{array}$ & GÉNERO & LITERATURA \\
\hline $\begin{array}{l}\text { KHAYYAM, Omar } \\
(1048-1131)\end{array}$ & Los Rubayata & $\begin{array}{l}\text { Núm. I } \\
\text { (marzo) }\end{array}$ & Poesía & $\begin{array}{l}\text { Persa [Trad. a par } \\
\text { tir de una versión } \\
\text { anglosajona] }\end{array}$ \\
\hline $\begin{array}{l}\text { LONGFELLOW, } \\
\text { Henry Wadsworth } \\
\text { (1807-1882) }\end{array}$ & $\begin{array}{l}\text { Poesías: } \\
\text { - “Día de lluvia" } \\
\text { - "Huyóse el día" } \\
\text { - “No siempre es mayo" } \\
\text { - "Himno a la noche" }\end{array}$ & $\begin{array}{l}\text { Núm. } \\
\text { (abril) }\end{array}$ & Poesía & Norteamericana \\
\hline $\begin{array}{l}\text { MALLARMÉ, Stépha- } \\
\text { ne } \\
(1842-1898)\end{array}$ & $\begin{array}{l}\text { Poemas en prosa: } \\
\text { - "El fenómeno futuro" } \\
\text { - "La pipa" } \\
\text { - "Queja de otoño" } \\
\text { - "Estremecimiento de invier- } \\
\text { no" }\end{array}$ & $\begin{array}{l}\begin{array}{l}\text { Núm. III } \\
\text { (mayo) }\end{array} \\
\end{array}$ & Prosa poética & Francesa \\
\hline $\begin{array}{l}\text { POE, Edgar Allan } \\
(1809-1849)\end{array}$ & Filosofía de la composición & $\begin{array}{l}\text { Núm. X } \\
\text { (diciembre) }\end{array}$ & Ensayo & Norteamericana \\
\hline
\end{tabular}




\begin{tabular}{|c|c|c|c|c|}
\hline $\begin{array}{l}\text { AUTORES } \\
\text { TRADUCIDOS }\end{array}$ & TEXTOS & $\begin{array}{c}\text { NÚMERO Y } \\
\text { FECHA }\end{array}$ & GÉNERO & LITERATURA \\
\hline $\begin{array}{ll}\text { THOREAU, } & \text { Henry } \\
\text { David } & \\
(1817-1862) & \\
\end{array}$ & $\begin{array}{l}\text { La vida en los bosques: } \\
\text { - "Soledad" }\end{array}$ & $\begin{array}{l}\text { Núm. II } \\
\text { (abril) }\end{array}$ & Narrativa & Norteamericana \\
\hline $\begin{array}{l}\text { VERLAINE, Paul } \\
(1844-1896)\end{array}$ & $\begin{array}{l}\text { Poesías: } \\
\text { - "Serenata" } \\
\text { - “Arietas olvidadas" } \\
\text { - “Gaspard Hauser canta" } \\
\text { - "La canción de las ingenuas" } \\
\text { - "Spleen" }\end{array}$ & $\begin{array}{l}\text { Núm. VII } \\
\text { (septiembre) }\end{array}$ & Poesía & Francesa \\
\hline
\end{tabular}

\section{Bibliografía}

1. Aguilera, J. y Herrero, R. (eds.) (1995). Homenaje del Ateneo Riojano a María de la O Lejárraga (María Martínez Sierra, 1874-1974). Logroño: Ateneo Riojano.

2. Aguilera, J. (coord.) (2002). María Martínez Sierra y la República: ilusión y compromiso. Logroño: Instituto de Estudios Riojanos.

3. Aguilera, J. (2006). Ante la República: conferencias y entrevistas (1931-1932). Logroño: Instituto de Estudios Riojanos.

4. Aguilera, J. (2007). Juan Aguilera estudia a María Lejárraga (entrevista realizada por José Luis Campal). La Ratonera. Revista asturiana de teatro, 20: 110-119.

5. Aguilera, J. (2008). La Asociación Femenina de Educación Cívica (1931-1936). María Martínez Sierra: feminismo y música. III Jornadas sobre María Lejárraga. 2427 de octubre y 14-17 de noviembre de 2005. Juan Aguilera (coord.). Logroño: Instituto de Estudios Riojanos: 79-142.

6. Arana, V. (1876). Oro y oropel (Joyas literarias extranjeras y trabajos originales, poemas, leyendas). Bilbao: Imprenta Lib. y Lit. de Juan E. Delmas.

7. Ayén, X. (2000). Esposa y negra en la vida, La Vanguardia, 17 de noviembre.

8. Bianchi, M. (2006). La tragedia de la perra vida: María Martínez Sierra contándose a sí misma. Teatro y mujer en España. De los años 20 a la posguerra. Actas del Seminario Internacional. Bérgamo, 2 de diciembre de 2005. Margherita Bernard (ed.). Bérgamo: Bérgamo University Press - Sestante Edizioni, pp. 97-116.

9. Bowra, C.M. (1972). La imaginación romántica. Versión española de José Antonio Balbontín. Madrid: Taurus.

10. Blanco, A. (1999). María Martínez Sierra (1874-1974). Madrid: Ediciones del Orto.

11. Blanco, A. (2001). María Martínez Sierra: feminismo y exilio. El exilio literario de 1939. María Teresa González de Garay Fernández y Juan Aguilera Sastre (eds.). Universidad de La Rioja-Gexel: Logroño, pp. 359-373.

12. Blanco, A. (ed.) (2003). A las mujeres: ensayos feministas de María Martínez Sierra. Logroño: Instituto de Estudios Riojanos. 
13. Blanco, A. (ed.) (2006). María Martínez Sierra: hacia una lectura de su vida y obra. Arbor: Ciencia, pensamiento y cultura, núm. 719, pp. 337-345.

14. Celma, M.P. (1989). La pluma ante el espejo. (Visión autocrítica del "Fin de Siglo", 1888-1907). Salamanca: Universidad de Salamanca.

15. Celma, M.P. (1991). Literatura y periodismo en las revistas del Fin de Siglo. Estudio e indices (1888-1907). Madrid: Júcar.

16. Clavería, C. (1970). Unamuno y Carlyle. Temas de Unamuno. Madrid: Gredos: 7-62.

17. Coletes, A. (2001). Más sobre Tagore en España: una traducción olvidada (inglésespañol) de Martínez Sierra. Archivum: Revista de la Facultad de Filología, tomo 50-51: 119-148.

18. Chas, R.A. ¿Por qué no firmó María Martínez Sierra las obras que escribió con su marido? Sin título, sin fecha, sin página. Recorte de un artículo de periódico. Archivo familiar Lejárraga. Madrid.

19. Checa, J.E. (2009). María Martínez Sierra: una escritora en el exilio. Foro Hispánico: revista hispánica de Flandes y Holanda. Ejemplar dedicado a: Roles de género y cambio social en la Literatura española del siglo XX, 34: 207-228.

20. Díaz Pérez, V. (1904). Notas y ensayos de una traducción de El cuervo de Edgardo Poe. Helios, XII: 347-354.

21. Díaz-Plaja, Guillermo (1966). Modernismo frente a Noventa y ocho. Madrid: EspasaCalpe.

22. Englekirk, J.E. (1934). Edgar Allan Poe in Hispanic Literature. New York: Instituto de las Españas en los Estados Unidos.

23. Englekirk, J.E. (1942). Notes of Longfellow in Spanish America. Hispania: A Quaterly Journal devoted to the interests of teachers of Spanish. Stanford University, vol. III, núm. 25: 295-308.

24. Fernández, P. (1999). La editorial Garnier de París y la difusión del patrimonio bibliográfico castellano en el siglo XIX. Miscelánea léxica en memoria de Conchita Serrano. Madrid: CSIC, pp. 603-612.

25. Fischer, D. (1995). El libro español en París a comienzos del siglo XX. Escritores y traductores. Tesis doctoral. Inédita. Universitat Rovira i Virgili.

26. Fuster, E. (2003). El mercader de ilusiones. La historia de Gregorio Martínez Sierra y Catalina Bárcena. Madrid: Sociedad General de Autores y Editores.

27. Fuster, E. (2007). María Martínez Sierra o la iluminada penumbra. Teatro y Literatura. Madrid: Legados, pp. 57-81.

28. González Ródenas, S. (2005). Juan Ramón Jiménez a través de su biblioteca. Lecturas y traducciones en lengua francesa e inglesa (1881-1936). Sevilla: Secretariado de Publicaciones de la Universidad de Sevilla.

29. González Ruano (2004). Memorias. Mi medio siglo se confiesa a medias. Sevilla: Renacimiento.

30. Gullón, R. (1961). Relaciones amistosas y literarias entre Juan Ramón Jiménez y los Martínez Sierra. Universidad de Puerto Rico: Ediciones de la Torre. 
31. Jiménez, J.R. (2006a). Epistolario I 1898-1916. Alfonso Alegre Heitzmann (ed.). Madrid. Publicaciones de la Residencia de Estudiantes.

32. Jiménez, J.R. (2006b). Música de otros. Traducciones y paráfrasis. S. González Ródenas (ed.). Barcelona: Galaxia Gutenberg - Círculo de Lectores.

33. Lanero, J.J. y Villoria, S. (1996). Henry Wadsworth Longfellow (1807-1882). Literatura en traducción. Versiones españolas de autores americanos del s. XIX. León: Secretariado de Publicaciones de la Universidad de León, pp. 145-162.

34. Lanero, J.J., Santoyo, J.C. y Villoria, S. (1993). 50 años de traductores, críticos e imitadores de Edgar Allan Poe (1857-1913). Livius: Revista de estudios de traducción, 3: 159-184.

35. Lizárraga, I. (2004). María Lejárraga. Pedagogía, cuentos breves y otros textos. Logroño: Instituto de Estudios Riojanos.

36. Longfellow, H.W. (2002 [1907]). Poesías. Renacimiento, núm. II, pp. 253-254.

37. López Martínez, M.I. (2006). María de la O Lejárraga: la voz suplantada. Teatro y mujer en España. De los años 20 a la posguerra. Actas del Seminario Internacional. Bérgamo, 2 de diciembre de 2005. Margherita Bernard (ed.). Bérgamo: Bérgamo University Press - Sestante, pp. 19-33.

38. Llorente, T. (1875). Leyendas de Oro. Poesías de los principales autores modernos, vertidas en rima castellana por Teodoro Llorente. Valencia: Pascual Aguilar, Impr. Doménech.

39. Martínez Sierra, G. (1999). Teatro de ensueño. La intrusa (de Maurice Maeterlinck). Serge Salaün (ed.). Madrid: Biblioteca Nueva.

40. Martínez Sierra, M. (2000). Gregorio y yo. Medio siglo de colaboración. Valencia: Pre-textos.

41. Martínez Sierra, M. (2009). Tragedia de la perra vida y otras diversiones: teatro del exilio 1939-1974. J. Aguilera Sastre e I. Lizárraga (eds.). Sevilla: Renacimiento.

42. Montes, F. (1994). A propósito de una traducción de Henry David Thoreau a principios del siglo XX. Livius: revista de estudios de traducción, 5: 145-152.

43. Nervo, A. (1907). Una poesía de Edgard Pöe. Ateneo, tomo III, abril, p. 334.

44. Nieva de la Paz, P. (1999). Y María tres veces amapola María (1998), de Maite Aguirre: una visión del testimonio histórico y existencial de María de la $\mathrm{O}$ Lejárraga (1874-1974). Teatro histórico (1975-1998): textos y representaciones. José Romera Castillo y Francisco Gutiérrez Carbajo (eds.). Madrid: Visor Libros, pp. 399-408.

45. Obiol, M.J. (2000). La autora oculta. El País, 23 de septiembre.

46. O'Connor, P. (1987). Gregorio y María Martínez Sierra: Crónica de una colaboración. Madrid: La Avispa.

47. O'Connor, P. (2003). Mito y realidad de una dramaturga española: María Martínez Sierra. Logroño: Instituto de Estudios Riojanos.

48. O'Riordan, P. (1970). Helios, revista del modernismo (1903-1904). Ábaco. Estudios de literatura española. Madrid: Castalia, pp. 57-150.

49. Paz, O. (1993). Los hijos del limo. Del romanticismo a la vanguardia. Barcelona: Seix Barral. 
50. Paz, Ramón (1950). Revista Contemporánea: Madrid 1875-1907. Madrid: CSIC, Instituto Miguel de Cervantes.

51. Pérez Romero, C. (1979). Raíces norteamericanas en la obra de Juan Ramón Jiménez: E. A. Poe y la poesía juanramoniana. Anuario de Estudios Filológicos, II, Cáceres: Universidad de Extremadura, pp. 211-229.

52. Pérez Romero, C. (1987). Juan Ramón Jiménez, poeta-traductor: historia de un "proyecto", Fidus Interpres: Actas de las primeras jornadas nacionales de historia de la traducción. Universidad de León: 120-128.

53. Pérez Romero, C. (1992). Juan Ramón Jiménez y la poesía anglosajona. Extremadura: Universidad de Extremadura.

54. Poe, E.A. (1887). El cuervo, traducción directa del inglés por J.A. Bonalde. New York: American Publishing Company.

55. Poe, E.A. (1904). El cuervo. Helios, núm. XII, pp. 457-462.

56. Poe, E.A. (1909). Poemas. Traducciones de Carlos Arturo Torres y J. Pérez Bonalde. Prólogo de Rubén Darío. Madrid: Impr. Primitivo Fernández (Colección Apolo). Madrid.

57. Poe, E.A. (2002 [1907]). Filosofía de la composición. Renacimiento, núm. X: 12791294.

58. Renacimiento (2002 [1907]). 10 números, edición facsímil, Luis García Montero (pról.). 2 tomos. Sevilla: Editorial Renacimiento.

59. Rodrigo, A. (1994). María Lejárraga, una mujer en la sombra. Madrid: Ediciones Vosa.

60. Rodríguez, E. (2000). El escritor era ella. El Mundo. 27 de noviembre.

61. Rodríguez Guerrero-Strachán, S. (1999). Presencia de Edgar Allan Poe en la literatura española del siglo XIX. Valladolid: Secretariado de Publicaciones e Intercambio Científico de la Universidad de Valladolid.

62. Sastre, J.A. (2008). La Asociación Femenina de Educación Cívica (1931-1936). María Martínez Sierra: feminismo y música, III Jornadas sobre María Lejárraga, Logroño 24-27 de octubre y 14-17 de noviembre de 2005, pp. 79-142.

63. Thoreau, H.D. (1854). Walden; or, Life in the Woods, Boston: Ticknor and Fields.

64. Thoreau, H.D. (1945). Walden o la vida en los bosques. Traducción por Julio Molina Vedia, Buenos Aires: Emecé.

65. Thoreau, H.D. (1949). Walden o mi vida entre bosques y lagunas. Traducción por Justo Gárate, Buenos Aires: Espasa-Calpe.

66. Thoreau, H.D. (2002 [1907]). La vida en los bosques. Soledad, Renacimiento, núm. II, pp. 224-235.

67. Umbral, F. (2000). Las escritoras. Tiempo de hoy. 27 de noviembre.

68. Verlaine, P. (s.a.). Fiestas galantes. Poemas saturnianos: La buena canción. Romanzas sin palabras, Sabiduría, Amor, Parábolas y otras poesías. Precedidas de un prefacio de François Coppée, traducidas al castellano por Manuel Machado, Prólogo de Enrique Gómez Carrillo. Madrid: Librería de Fernando Fé.

69. Wortham, T. (1991). William Cullen Bryant y los "Poetas Domésticos". Historia de la literatura norteamericana. Emory Elliot (ed.). Madrid: Cátedra, pp. 278-288. 
70. Young, H. (1976). Anglo-american poetry in the correspondence of Luisa and Juan Ramón Jiménez. Hispanic Review, 44: 1-26.

71. Young, H. (1981). The exact names. Modern Language Notes, 92: 212-223. 